\title{
Divergent processes and trends of desertification in Inner Mongolia and Mongolia
}

Xiaona Guo ${ }^{1.2}$, Ruishan Chen ${ }^{1 *}$, David S.G. Thomas ${ }^{2,3}$, Qiang Li ${ }^{4}$, Zilong Xia ${ }^{1}$, Zhenzhen Pan ${ }^{5}$

${ }^{1}$ Key Laboratory of Geographic Information Science, Ministry of Education, and School of

Geographical Sciences, East China Normal University, Shanghai 200241, China

${ }^{2}$ School of Geography \& the Environment, University of Oxford, Oxford OX1 3QY, UK

${ }^{3}$ School of Geography, Archaeology and Environmental Studies, University of the Witwatersrand,

Johannesburg 2050, South Africa

${ }^{4}$ College of Environment and Planning, Henan University, Kaifeng 475001, China

${ }^{5}$ School of Resource \& Environment Science, Wuhan University, Wuhan 430079, China

*Correspondence

Ruishan Chen, Key Laboratory of Geographic Information Science, Ministry of Education, and School of Geographical Sciences, East China Normal University, 500 Dongchuan Road, Shanghai 200241, PR China. Email: chenrsh04@gmail.com 


\title{
Divergent processes and trends of desertification in Inner Mongolia
}

\author{
and Mongolia
}

\begin{abstract}
Desertification and the expansion of deserts are regarded as a major threat to human livelihood, ecosystem services, as well as achieving Sustainable Development Goals. Humans have also been recognized as a significant agent in the expansion of desert-like conditions, through the agency of desertification/land degradation processes, and through contributions to global climate change. Yet, how desertification changes and whether human or climate change drives these processes and trends over the whole Mongolia plateau is still not clear. Here we first use MODIS data for 2000-2019 to assess the long-term vegetation changes across the Mongolian Plateau, both in Inner Mongolia of China and the Mongolian People's Republic. We then apply a General Linear Model to analyze the additional climate and human attribute data sets to explore relationships between the observed desert extent reduction and their potential drivers. Results show that from 2000-2019, desert extent declined by over 7\%, comprised of an almost $11 \%$ reduction in Inner Mongolia, China, and 5\% reduction in Mongolia, and a reduction in the degree of desert conditions, as measured by vegetation cover grades, across the whole region (37.5\% descends one grade in China, 28.75\% in Mongolia). The majority of desert area reduction occurs in the northern and eastern areas of the Mongolia plateau. We found that the main driver of changing desert extent is not because of a reduction in human pressures on the land, but an increasing trend of both precipitation and temperature, which explains over $75 \%$ of all the observed changes. Besides, urbanization, and a reduction of population pressures on the land, contribute to most of the remaining changes. Our results suggest that although the climate has been the primary driver of changing desert area and severity, human interventions have played an important role, although the way how it intervenes and the intensity varies in Inner Mongolia and Mongolia. Human's active response to land degradation in the desert contributes to more land restoration in Inner Mongolia than in Mongolia.

KEYWORDS: desertification, vegetation restoration, climate change, human interventions, Mongolia plateau
\end{abstract}

\section{1 | INTRODUCTION}

Desertification refers to land degradation that involves at least one of three long-term losses, biological productivity, ecological integrity, and in the land's value to humans in arid, semi-arid, and dry sub-humid areas caused by climatic variations and human activities (IPBES, 2018; UNCCD, 1994). It was the first major terrestrial environmental issue which has received structured attention via the United Nations, through its Conference on Desertification (UNCOD) in 1977. Identifying the scale, extent, and drivers of desertification is closely linked with other vital socio-environmental issues, such as climate change, environmental and food security, poverty, and human well-being (Mirzabaev et al., 2019; Cherlet et al ., 2018). These linkages are recognized in global assessment including the first global assessment of land degradation and restoration of IPBES (Intergovernmental Science-Policy Platform on Biodiversity and Ecosystem Services); the new world atlas of desertification (WAD3) of European Commission's Joint Research Centre; special report on climate change and land of IPCC (Intergovernmental Panel on Climate Change); and the 
CoP14 of the UNCCD (the United Nations Convention to Combat Desertification) also focuses on land degradation and desertification (UNCCD, 2019). Desertification is a growing concern in drylands (Bestelmeyer et al., 2015). However, the process and trends of desertification in drylands on a regional scale are still not clear. Therefore, this study aims to examine the trend of desertification in the Mongolia plateau and identify the potential driving forces.

Both climate and human intervention can affect desertification (Thomas, 1993; Thomas \& Middleton, 1994; Wang, Chen, Hasi, \& Li, 2008; Li, Wu, \& Huang, 2012), but the direction is not clear. The increasing temperature in drylands will increase potential evaporation, which exacerbates the desertification on dryland (Sherwood \& Fu, 2014; Huang, Yu, Guan, Wang, \& Guo, 2015). But the rising precipitation can also increase vegetation coverage in the drylands (Zhang et al., 2018). The combined effects of changing temperature and precipitation on desertification are not fully explored. Human actions play an additional and complicated role in desertification as irresponsible land-use change can expand the desert (Bestelmeyer et al., 2015), but human activities through sustainable management of the dryland can also restore the degraded land (Miao et al., 2015). Thus, what's the specific contribution of climate change and human intervention to desertification is a question needed to be carefully examined.

The desert over the entire Mongolia plateau region has experienced great changes in the past several decades. There are indications that the extent of desert areas in China as a whole has declined by $12,120 \mathrm{~km}^{2}$ from 2009 to 2014, at an annual reduction rate of $2424 \mathrm{~km}^{2}$ (SFAC, 2015). In Inner Mongolia, desertification reached its maximum in the 1970s and early 1980s and then began to fall from the late 1980s (Miao et al., 2015; Wang, Chen, Hasi, \& Li, 2008). There is evidence that hydrothermal regimes improved and wind velocities (responsible for aeolian sediment transport) declined since the 1980s (Xu, Song, Li, Ding, \& Wang, 2019), leading to enhanced vegetation cover in previously dry areas (Ren, Tan, \& Zhang, 2019; Sherwood \& Fu, 2014). Also, efforts to reduce land degradation has increased even early (Chen et al., 2015). China started to combating desertification since at least the 1950s and spent at least 60 billion Chinese yuan per year on various land restoration projects (Cheng et al., 2018). The Green Great Wall project, for example, has planted 66 billion trees in North China which has increased the world's forested area by $10 \%$ (Petri, 2017). Other interventions including the introduction of more sustainable farming, grazing, and water management practices, and the establishment of windbreaks have also been applied to combat desertification (Chen et al., 2019; Zhang \& Huisingh, 2018; Zhou et al., 2015). Due to these contributions, China has won the 2015 Land for Life Award for true influencers on fighting land degradation by UNCCD (UNCCD, 2015).

However, there have been more limited assessments of desertification in the Mongolian People's Republic. Researches found that the natural, political, social, and economic factors, the natural environment can be quite different across sides of country boundaries (Wuepper, Borrelli, \& Robert Finger, 2020). Wang et al. (2019) assessed land cover changes in Mongolia from 1990-2010, concluding that land degradation has become severe in that period, which has also experienced declining precipitation and increasing temperatures (Filei, Slesarenko, Boroditskaya, \& Mishigdorj, 2018). In contrast, Sternberg et al. (2015) have used the aridity index to examine the changing extent of the Gobi Desert and found a decrease in the desert in the period 2002-2012. The potential 
differences in desertification trends in the China and People's Republic of Mongolia parts of the Mongolian Plateau, and discrepancies in the findings of some recent studies, indicate that the analysis of desert trends over the whole plateau (not some parts of the region) is really needed. Besides, given that climate variations and human activities can cause an apparent change of extent of deserts over time, it can be difficult to distinguish between the drivers of the changes at any particular time in a specific location, which is also an urgent problem to be solved.

Thus, this study aims to detect the long-term, not the short-term, desertification processes and trends across the whole plateau under the background of large-scale artificial restoration in Inner Mongolia and natural restoration in Mongolia, and to distinguish and quantify the contributions of climatic and direct human actions to change sin desert extent, not just figure out the possible drivers. To address this aim, first, based on MODIS/MCD NDVI data from 2000 to 2019, we use the Google Earth Engine Platform (GEE) and the Markov shift matrix model to identify trends, processes in dryland extent. Then, using a variety of data sets, we explore the contributions of climate and direct human actions to the observed changes, through correlation analysis and general linear modeling (GLM). This study could provide a reference for desertification management, and to achieving Land Degradation Neutrality of UNCCD and sustainable development goals of the UN.

\section{2 | STUDY AREA}

The Mongolian plateau $\left(87^{\circ} 43^{\prime} \mathrm{E}-126^{\circ} 04^{\prime} \mathrm{E}, 37^{\circ} 22^{\prime} \mathrm{N}-53^{\circ} 20^{\prime} \mathrm{N}\right)$ covers a total area of about 2.74 million $\mathrm{km}^{2}$, by 2017 supported a population of over 28 million and represents the fifth-largest desert area on earth, playing a crucial role in the global carbon cycle and climate system but also being prone to the risks of desertification (Chen, John, Shao, et al., 2015; FAO, 2020; Helldén \& Tøttrup, 2008; Li et al., 2008; IMARSB, 2018; White, Battisti, \& Roe, 2017). It has a temperate continental climate, with warm summers, but long and cold winters when snowfall is common and persistent. The annual average temperature varies from $-1.7{ }^{\circ} \mathrm{C}$ to $5.6{ }^{\circ} \mathrm{C}$ with temperature extremes also common, due to the region's elevation and continentality. Precipitation varies spatially and fluctuates from year to year from 90 to $433 \mathrm{~mm}$ and mainly distributes between May and September (Fernandez-Gimenez \& Allen-Diaz, 1999; Sternberg, Rueff, \& Middleton, 2015). Ecosystems vary from true desert to steppe and forested areas (John, Chen, Lu, \& Wilske, 2009). Compared with Mongolia, 2000-2018 is a very rapid development period in terms of GDP and urbanization in Inner Mongolia (Figure 1). In the past few decades, there has been rapid urbanization especially in Inner Mongolia, China, due to economic transformations as well as developments in the agricultural sector, which have in turn led to land-use changes (Chen, John, Shao, et al., 2015; John et al., 2015).

\section{3 | METHOD AND MATERIALS}

This study uses data to establish the processes and trends in desertification through the long-term period 2000-2019, the drivers of these trends, and their spatial variability.

\section{1 | Data}

\subsection{1 | Desertification data}

Our analysis of desertification trends is based on MODIS/MCD43A4_006_NDVI data from 2000 
to 2019. The Normalized Difference Vegetation Index (NDVI) is a remotely sensed measure of vegetation photosynthesis ranging from 0 (zero to sparse vegetation cover) to 1 (dense cover) (Chen et al., 2012). MODIS/MCD43A4_006_NDVI is the product of the MODIS version 6 MCD43A4

surface reflectance composites with a spatial resolution of $500 \mathrm{~m}$ (https://developers.google.com/earth-engine/datasets/catalog/MODIS_MCD43A4_006_NDVI)

which have been variously used to identify changes in vegetation, wetland, and runoff (Gumbricht, 2018; Haniyeh, Shahedi, Jarihani, \& Sidle, 2019; Wu, Sun, Epstein, Xu, \& Li, X., 2019). As May to September is the vegetation growth period on the Mongolian plateau and the stage when NDVI reaches its maximum annual values, we choose yearly max values of May-September NDVI as the basic data to evaluate changes in desertification (Guo et al., 2017), as suggested by Karnieli et al. (2013).

\subsection{2 | Driving factors data}

Taking account of available data and previous studies of desertification on the Mongolian Plateau (Feng, Ma, Jiang, Wang, \& Cao, 2015; Tao et al., 2015), we selected a series of potential drivers of changes in desertification extent. Data for human factors in Inner Mongolia including urbanization (urban population (UP), rural population (RP), built-up areas of cities (BAC)), grazing intensity (numbers of sheep and goats (NS)), and agricultural intensity (irrigated area (IA)) were documented from the Inner Mongolia Statistical Year Book, and those of Mongolia were obtained from the Food and Agriculture Organization of the United Nations database (faostat.fao.org).

Climate data for annual precipitation (AP), May to September precipitation (MSP), annual mean temperature (AMT), and May to September mean temperature (MSMT) were derived from ERA5 data((C3S), 2017). ERA5 is the fifth generation ECMWF atmospheric reanalysis of the global climate and provides aggregated values for each day from 1979 until the present for seven ERA5 climate reanalysis parameters including temperature and precipitation. Monthly or yearly air temperature has been calculated by averaging the daily or monthly minimum and maximum air temperature. Monthly or yearly total precipitation values are attained by summing daily or monthly data. All climate data in this paper is from 2000 to 2019. Details of the processing code are available from the authors.

\section{2 | Methods}

\subsection{1 | Vegetation fractional coverage}

In line with previous studies of large scale desert/desertification expansion and contraction (e.g. (Sternberg, Rueff, \& Middleton, 2015)) in the region, we use changes in vegetation cover as the key surrogate. This is justified on the grounds that vegetation cover is 1) the primary responder to changes in climate in deserts and desert margin areas (e.g. (Mayaud, Bailey, \& Wiggs, 2017; Thomas, Knight, \& Wiggs, 2005)), 2) changes in surface vegetation predispose landscapes to other desertifying agents such as wind and water erosion, including when caused by direct human agency, and 3) increases in vegetation cover is an indication of landscape recovery, whether caused by climate amelioration or human actions (Gang et al., 2019). From these data we determined the 
vegetation fractional coverage (VFC) according to Gutman and Ignatov (1998), see formula (1), to explore the desertification trend. VFC referring to the percentage of vegetation vertical projection area covering a study area is widely used to measure the changes of the ecological environment including land reclamation and vegetation recovery (Gu et al., 2015; Song et al., 2020; Zhang, Wang, $\& \mathrm{Li}, 2019)$. VFC data are scaled into five grades to indicate the severity of desertification: non (VFC $\geqslant 70)$, slight $(69>\mathrm{VFC}>50)$, moderate $(49>\mathrm{VFC}>30)$, severe $(29>\mathrm{VFC}>10)$, extremely severe $(\mathrm{VFC}<10$ ), according to the National Standards of P.R. China-Land Desertification Monitoring Method $\mathrm{GB} / \mathrm{T} 20483$

from http://c.gb688.cn/bzgk/gb/showGb?type=online\&hcno=62E00314AFED9EDF6BAC3562FA2AB 276. This part of the work is completed on the Google Earth Engine (GEE), the code is available from the authors.

$$
V F C=\frac{N D V I-N D V I_{\min }}{N D V I_{\max }-N D V I_{\min }}
$$

Where $V F C$ refers to vegetation fractional coverage (unit: \%); NDVI is the value of each grid; $N D V I_{\min }$ and $N D V I_{\max }$ represent the minimum value and maximum value of the grid, respectively.

\subsection{2 | Markov model}

We then explore the processes of desertification change using the Markov model that is commonly used to consider the processes and mechanisms of landscape dynamic change from a long-term perspective (Muller \& Middleton, 1994; Urban \& Wallin, 2017). We adopt a transition matrix that is the core part of the Markov model, see formula (2), which is generally applied to estimate land cover changes including the conversion process of desertification (Bai, Wang, \& Xiong, 2013; Zhu et al., 2018). While different conversions in the desertification process occur, we mainly pay close attention to the biggest converted values, which have significant impacts on desertification. In this paper, we find that the most common conversions are those from high grades of desertification to the adjacent low ones and from non-desert conditions to low grades of desertification. We also calculate the converted ratio of the main converted types through formula (3). These analyses were conducted in ArcGIS and R.

$$
\mathrm{T}=\left[\begin{array}{cccc}
D_{11} & D_{12} & \ldots & D_{1 n} \\
D_{21} & D_{22} & \ldots & D_{2 n} \\
\ldots & \ldots & \ldots & \ldots \\
D_{n 1} & D_{n 2} & \ldots & D_{n n}
\end{array}\right]
$$

where T refers to the conversion matrix of different grades of desertification from 2000 to 2019; $D_{n n}$ refers to the change in the area (unit: $\mathrm{km}^{2}$ ) from one grade of desertification to another during the period of analysis; and $\mathrm{n}$ refers to the area of certain grade desertification which was involved in the computation.

$$
R_{i j}=\frac{E_{i j}}{F_{i}}
$$

Where $R_{i j}$ refers to the rate of $i$ grade desertification converting to $j$ grade desertification; $E_{i j}$ 
represents that the area of $i$ grade desertification converting to $j$ grade, which is the biggest one of all converted values; $F_{i}$ is the total area of i grade desertification in 2000 (unit: $\mathrm{km}^{2}$ ).

\subsection{3 | Generalized linear model}

To establish the influence of different factors on desertification, we first performed a correlation analysis for desertification and driver data sets. We then conducted a Generalized linear model (GLM) regression to quantify the relative contribution of each variable to desertification. GLM regression extends linear model regressions by expanding the distribution range of dependent variables and introducing a continuous function and is generally applicable to non-normal data (Araromi, Majekodunmi, Adeniran, \& Salawudeen, 2018). As formulas (4), (5), and (6) show, the model is a function of mean $\mu$ with a linear combination $\mathrm{x}_{\beta}$ formed from repressor $\mathrm{x}$ and coefficient vector $\beta$. All statistical analyses were conducted in SPSS.

$$
\begin{gathered}
\mu_{i}=E\left(Y_{i} \mid X_{1}, X_{2}, \ldots, X_{k}\right), i=1, \ldots, n \\
\eta_{i}=\mathrm{g}\left(\mu_{i}\right) \\
\mathrm{g}\left(\mu_{i}\right)=\eta_{i}=\beta_{0}+\beta_{1} X_{i 1}+\beta_{2} X_{i 2}+\beta_{3} X_{i 3}+\cdots+\beta_{k} X_{i k}
\end{gathered}
$$

Where $X$ is explanatory variables (driving factors of desertification); $Y$ is dependent variables (the area of desertification); $\mu_{\mathrm{i}}$ is $\mathrm{n}$ independent samples subject to the exponential family of distributions; $\eta_{i}$ means $\mathrm{k}$ linear combination of explanatory variables; $\mathrm{g}\left(\mu_{i}\right)$ refers to a link function linking $\mu_{\mathrm{i}}$ and $\eta_{i}$.

\subsection{4 | Mann-Kendall (MK) test}

We conducted the widely used Mann-Kendall (MK) test method (Gichenje, \& Godinho, 2018; Akinyemi, Ghazaryan, \& Dubovyk, 2020; Touré et al., 2020) to test the significance of the longterm trends in time series. In the MK trend test, the original hypothesis $\mathrm{H}_{0}$ is that there are no trends; the alternative hypothesis is that there is a trend that could either be negative, positive, or non-null (Mann, 1945). Its statistic (S) is calculated by the following formula:

$$
\mathrm{S}=\sum_{i=1}^{n-1} \sum_{j=i+1}^{n} \operatorname{sgn}\left(x_{j}-x_{i}\right)=\left\{\begin{array}{c}
1, x_{j}>x_{i} \\
0, x_{j}=x_{i} \\
-1, x_{j}<x_{i}
\end{array}\right.
$$

where $n$ is time series length, $x_{j}$ and $x_{i}$ are the annual observations. For all $i, j \leqslant n$, and $i \neq j$, the distributions of $x_{j}$ and $x_{i}$ are different. The positive (negative) value of $S$ represents an increasing (decreasing) trend. The variance of $\mathrm{S}$ is calculated as follows:

$$
\operatorname{Var}(S)=n(n-1)(2 n+5) / 18
$$

If $\mathrm{n}$ is greater than 10 , the standard $\mathrm{Z}$ value for the MK test is calculated as follows:

$$
Z=\left\{\begin{array}{c}
\frac{S-1}{\sqrt{\operatorname{Var}(S)}}, S>0 \\
0, S=0 \\
\frac{S-1}{\sqrt{\operatorname{Var}(S)}}, S<0
\end{array}\right.
$$

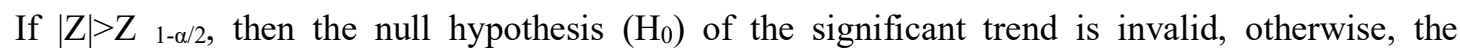


alternative hypothesis $\left(\mathrm{H}_{1}\right)$ shows no significant trend. In a positive (upward) trend, $\mathrm{Z}$ is positive, and a negative $Z$ value indicates a downward trend. When $Z$ absolute value is greater than or equal to $1.28,1.64$, and 2.32 , it indicates that the result passes the $0.1,0.05$, and 0.01 significance test, respectively.

In this study, we tested the significance of the desertification trends and driving factors with MK. Desertification shows a decreased trend both in Inner Mongolia and Mongolia, which passed the significance test of 0.01 and 0.05 , respectively (Table 1). For the trends of influence factors, NS, UP, RP, BAC, and IA in Inner Mongolia all passed the 0.01 significance test; NS and UP in Mongolia also passed the significance test of 0.01 ; RP in Mongolia passed the 0.05 significance test; while for MAMT, AMT, MSP, and AP, their trends are not so significant.

\section{4 | RESULTS}

\section{1 | Reduction in the degraded area}

This analysis shows that the desertified area of the Mongolian Plateau as a whole decreased from 2000 to 2019 (Figure 2 and Table 2), with a net fall in the desert area of 167,623 $\mathrm{km}^{2}$ since 2000, equivalent to almost $75 \%$ of the area of the United Kingdom. $58.56 \%$ of this reduction has occurred in Inner Mongolia, China, exceeding the reduction in Mongolia by $28,706 \mathrm{~km}^{2}$. Reductions have largely occurred in the northern and eastern regions of the plateau (Figure 2).

The net reduction of the desert area of Inner Mongolia was $98,165 \mathrm{~km}^{2}$ between 2000 and 2019, a decrease of almost $11 \%$. In Mongolia, the net decline of $69,459 \mathrm{~km}^{2}$ has primarily been due to the reduction of extremely severe degraded areas by $29.75 \%$. The declines in the areas of extremely severe and moderate desertification are $118,432 \mathrm{~km}^{2}$ and $163,083 \mathrm{~km}^{2}$, respectively. Because declining areas of specific desertification classes are achieved by shifts from one grade of desertification to another, these figures exceed the net reduction value of the overall desert area.

There was a divergence in the interannual change of the desertification area between Inner Mongolia and Mongolia. From 2000 to 2004, the desertified area for Inner Mongolia gradually dwindled down first and then increased abruptly, while for Mongolia it first decreased and then increased, and shrunk again, slowly. In 2005-2007, a sharp rise in the desertification area in Inner Mongolia, and fluctuations in Mongolia (fell firstly and then rose) was observed. During 2008-2011, the trend of desertification in Inner Mongolia is almost the same as that in Mongolia, the reason is that the trend of AP and MSP in Inner Mongolia was identical with that in Mongolia during the same period. Between 2012 and 2015, a slight increase in the desert area for Inner Mongolia and large volatility for Mongolia (increased first and then decreased sharply) was detected. 2016 is the peak of desert area for Inner Mongolia but the valley for Mongolia, the reason is that AP and MSP in the former fell off a little than last year but increased $17 \%$ and $12 \%$ in the latter, respectively. From 2017 to 2019, the desertification area for Inner Mongolia decreased firstly and then increased, while it decreased gradually in Mongolia. It is noteworthy that the maximum of desertification for Inner Mongolia and Mongolia both appeared in 2007, its minimum value was in 2018 for the former and 2012 for the later.

\subsection{The gradation of desertification reduction}


We use the Markov shift matrix to explore the processes contributing to desertification changes between 2000 and 2019. The most significant changes in desertification on the Mongolian Plateau are transitions between adjacent grades from more severe desertification to the lower grades, although there are transitions at all grades. Apart from a relatively small change of non-desert areas to areas that are slightly desertified, all the other desertification grades are transformed to one grade lower, indicating an overall reduction in the severity of desertification on the plateau. Compared with Mongolia, desertification in Inner Mongolia shows a more distinctive reverse trend, with the mean rate of descending one grade in Inner Mongolia of 37.5\% exceeding that in Mongolia (28.75\%) by almost $10 \%$.

The majority of the transition of non-desert land to slightly desertified land has occurred in Mongolia with only $1 \%$ of the land area of Inner Mongolia experiencing this trend compared to $7 \%$ in Mongolia. At the other end of the scale, the conversion ratio from extremely severe to severe desertification in Mongolia is higher (39\%) than in Inner Mongolia (32\%), however, the downward transition rates of all the other desertification grades are lower in Mongolia that in Inner Mongolia (Figure 3).

\section{3 | Spatial heterogeneity of changing desertification}

The geographical distributions of desertification changes on the Mongolia Plateau are detailed in Figure 4. In general, most of the reductions have occurred in the northern and eastern parts of the plateau. For example, in Inner Mongolia, Chifeng in the south-east has the biggest decline in total desertified land $\left(23,460 \mathrm{~km}^{2}\right)$, while Wuhai in the west experiencing the lowest reduction, by an insignificant $42.84 \mathrm{~km}^{2}$. In Mongolia, the net decrease is greatest in Dornod (north-east) at 21,353.1 $\mathrm{km}^{2}$, while barely any decrease was recorded in Omnogovi in the south $\left(2.21 \mathrm{~km}^{2}\right)$. When the severity classes are considered, however, the greatest reductions in the most severe desertification generally have occurred in western areas. For example, Bayan Nur in western Inner Mongolia and Omnogovi in south Mongolia see the greatest reduction of extremely severe desertification area, with 20,582.99 $\mathrm{km}^{2}$ and $10,597.12 \mathrm{~km}^{2}$, respectively. Overall, within the dimension of space, desertification restorations of Inner Mongolia are better than those of Mongolia, as total desertification of most municipalities/leagues in Inner Mongolia has decreased significantly in the past 20 years, while some in Mongolia has increased. The one major exception to this is Alxa League in inner Mongolia where there has been a notable transition in the area experiencing severe desertification to extremely severe desertification.

\section{4 | Attributing causation to declining desertification}

We have assessed the roles of climate change and human activities in the changing extent of desert conditions on the Mongolian Plateau. Climatic factors include total annual precipitation (AP), precipitation in the growing season, May to September (MSP), annual mean temperature (AMT), and growing season temperature (May to September) (MSMT). Unlike other studies of changes in the area of the Gobi Desert (Sternberg \& Edwards, 2017) or in desert conditions in part of the plateau (e.g. (Gong et al., 2020)), we also directly consider the role of potentially key human drivers of change across the whole plateau region. These include representative measures of agricultural activity in terms of grazing 
intensity (numbers of sheep and goats (NS), and agricultural intensity (irrigated area (IA), and measures of population pressure and spatial changes in population distributions, rural population (RP), urban population (UP) and the extent of towns and cities (built-up areas of cities (BAC)), see Figure 5.

We first conducted a correlation analysis between the desertification trend and influence factors (Table 3). In the last two decades, a fluctuated upward trend in MSP for both Inner Mongolia and Mongolia, a slight increase in ATM, and a modest decrease in MSMT (2010-2015) have been observed (Figure 5a-d). MSP $(\mathrm{P}<0.01$ in Inner Mongolia) and MSMT $(\mathrm{P}=0.048$ for Inner Mongolia, and $\mathrm{P}=0.03$ for Mongolia) have hastened desertification changes of the plateau since 2000. Both Inner Mongolia and Mongolia have seen a consistent increase in UP and a significant decrease in RP, although RP in Mongolia showed a slight increase after 2010 (Figure 5e). Besides, Inner Mongolia has experienced a steady increase in BAC (Figure 5f). This rapid advancement of urbanization in Inner Mongolia has a more obvious relationship with desertification reduction than in Mongolia ( $\mathrm{P}=0.018$ for UP, $\mathrm{P}=0.017$ for $\mathrm{RP}$, and $\mathrm{P}=0.014$ for $\mathrm{BAC}$ ). In addition, IA shows a marked increase in Inner Mongolia, although there is a sudden drop in 2013, which significantly negatives with the desertification area $(\mathrm{P}<0.005)$. During the study period, grazing intensity in both regions has increased (Figure $5 \mathrm{~g}$ ). However, grazing seems to have greater impacts on desertification in Inner Mongolia $(\mathrm{P}=0.026)$ than that in Mongolia.

To quantify the contribution of the different driving forces to land restoration, we also applied a general linear model. We can see from Table 3 that climate factors appear to have been more significant in the decrease in desert areas more than human interventions. $77.98 \%$ and $74.44 \%$ of the land restoration that has occurred in Inner Mongolia and Mongolia, respectively is attributable to climate drivers, particularly enhanced precipitation as represented in annual and May-September contributions. When it comes to human factors on the ground, in both Inner Mongolia and Mongolia, urbanization parameters correlate with enhanced land restoration, accounting for $9.52 \%$ in Inner Mongolia (principally measured by the growth in built-up areas, representing $9.44 \%$ of this total), and $13.28 \%$ in Mongolia. Grazing changes account for only 3.26\% of restoration in Inner Mongolia but $12.28 \%$ in Mongolia. The expansion in the irrigated land area in Inner Mongolia can be attributed to $9.24 \%$ of the decrease of desertification.

\section{5 | DISCUSSIONS}

\section{1 | Links between climatic factors and desertification}

The overall amount of desert area both in Inner Mongolia and Mongolia showed a decreasing trend from 2000 to 2019, but there was a divergence in its interannual change between the two regions, during which climate change especially the precipitation plays a vital role. Over the past 20 years, both mean annual temperature and precipitation in growing season show slight increases across the Mongolian Plateau as a whole (Figure 5). However, they have different roles in revegetation. It can be seen from Figure 5 and Figure 6 that the increase of precipitation in recent years is likely to be a key reason for the decrease in the desert area on the plateau, as noted by Sternberg and Edwards (2017). Greater annual precipitation levels could facilitate vegetation growth by enhancing net primary production or aboveground biomass (Zhang et al., 2013). The increasing precipitation could increase soil moisture, thus it is propitious to plants growth, especially the shallow ones (Yang et 
al., 2011). Higher precipitation in the growing season could provide enough soil moisture for vegetation restoration (Pang, Wang, \& Yang, 2017). While the rising temperature could produce complicated impacts on vegetation amelioration in the whole region. The rising annual mean temperature will affect the snow cover in the winter and how long it lies on the ground in the spring (Hammond \& Kampf, 2020). Higher winter/spring temperatures, reducing the time snow is on the ground and extending the growing season, which has a positive impact on desert reverse (Mellander, Löfvenius, \& Laudon, 2007). It may also assist in vegetation survival through what remains relatively harsh winter months, by reducing plant damage by frost and extending the growing season (Piao, Mohammat, Fang, Cai, \& Feng, 2006; Woldendorp, Hill, Doran, \& Ball, 2007).

In line with observations that northwest China has been getting warmer and wetter in recent decades (Shi et al., 2007), precipitation increases have played the most significant role in desert reduction and pasture improvement (Jobbágy, Sala, \& Paruelo, 2002; Munkhtsetseg, Kimura, Wang, \& Shinoda, 2007; Wang et al., 2019), though there is evidence in the data that effects may have in part been offset by temperature increases, particularly in Mongolia. For example, rising temperatures could cause droughts (Hirschi et al., 2011) and hot waves (Hauser, Orth, \& Seneviratne, 2016), which is extremely unfavorable for vegetation growth. In addition, according to the IPCC's 5th assessment report, and other two special reports, Global Warming of $1.5{ }^{\circ} \mathrm{C}$ and Climate Change and Land, the warming and wetting trend in the region is projected to continue, such that the extent of desert conditions in the Mongolian plateau may continue to decrease over coming decades.

\section{2 | Human interferences}

In terms of human activities, urbanization in Inner Mongolia has likely had an important indirect effect on vegetation restoration, which is consistent with the previous research (Ehrhardt-Martinez, Crenshaw, \& Jenkins, 2002). Urbanization and rural population reductions have alleviated the human pressure on the desert and have significant roles to combat desertification on the Mongolia plateau. Inner Mongolia has experienced rapid urbanization in the past two decades, with a doubling in the size of builtup areas. The $57 \%$ increase in the urban population has seen an associated fall in the rural population by $30 \%$ (Figure $4 \mathrm{e}$ ). This contributes to a reduction in agricultural and grazing pressures in marginal areas, and an increase in rewilding (Jorgenson \& Burns, 2007). From 2000 the Inner Mongolian government commences a resettlement programmer, with 200,000 poorer farmers and herders moved from degraded areas to urban and less-degraded rural areas to break the poverty-land degradation nexus (Dong, Liu, \& Klein, 2012). The reduction of pastoral pressures and pastoralist numbers could help promote vegetation restoration (Liu, 2002), although this scheme has also shown unintended ecological changes, including effects on water demand created by cities (Fan, $\mathrm{Li}, \& \mathrm{Li}, 2015$ ).

Grazing intensity in both Mongolia and Inner Mongolia has increased from 2000 to 2017, but it appears to have had different effects on desertification, which may due to the different grazing methods. While livestock numbers have risen in Mongolia, traditional, nomadic, practices remain dominant, with this extensive approach limiting pressure on the landscape (Zhang, Borjigin, \& Zhang, 2007). In contrast, livestock production in Inner Mongolia is more commonly carried out on-farm units, where parts of environmental pressures are shifted to the outside as imported grass has become an important source of feedstock (Chen, Shao, Zhao, Zhang, \& Zhang, 2017), which 
alleviates some pressure on grassland. Direct grazing effects appear to be relatively small in terms of contributing to desertification, contrary to widespread views that herding has been a major contributor to land degradation in inner Mongolia (e.g. (Ren, Shen, Lu, Wen, \& Jian, 2007)). Besides, in Mongolia, our data verifies a previous filed and remote sensing-based survey that the extensive nature of pastoralism makes it a limited contributor to the extent of desert conditions (Sternberg, Tsolmon, Middleton, \& Thomas, 2011). Though at shorter, annual timescales pastoralism itself may be impacted by events such as droughts and dzud (Sternberg, 2008) that are not captured within our longer-term analysis, livestock numbers are not in themselves are a significant contributor to desertification or desert extent changes across the region. An effective irrigated area of Inner Mongolia can help combat desertification. Irrigated lands can effectively guarantee farmland yield, with rainfall increasing, farmers can support themselves without reclaiming new wasteland that may consume water (Graves, Rosa, Nouhou, Maina, \& Adoum, 2019). In this way, limited soil and water are conserved, vegetation begins to restore.

\section{6 | CONCLUSIONS}

We have provided the first assessment of the relative contributions of climatic and human factors to changes in desert extent on the Mongolian Plateau. For the period 2000-2019, our analysis has used MODIS/MCD43A4_006_ data to assess year-on-year vegetation fractional changes across the Mongolian Plateau. This has first been to establish changes in the desert extent and desertified land and then investigate the potential drivers of change in terms of climate factors and human agency. The principal finding is that there has been a significant reduction in desertified, and in the severity of desertification in areas that remain as a desert. A divergent interannual change of desertification between Inner Mongolia and Mongolia has been detected. Changes have largely been observed in the north and east of the Plateau, in both Mongolia, where extent has reduced by almost 5\%, and in China, where an almost $11 \%$ reduction has been identified. The mean rate of moving down one grade is $37.5 \%$ in China and almost $28.75 \%$ in Mongolia, that is, a reduction in desertification severity. This study suggests that desert extent and desertification recovery can occur over large areas, over relatively short timescales, as demonstrated by the analysis of vegetation cover trends on the Mongolian Plateau. However, it appears that rather than largely being attributable to direct human actions on the ground, change in precipitation amounts play a key role in the reduction in desert extent.

\section{DECLARATION OF COMPETING INTEREST}

None.

\section{REFERENCES}

Araromi, D., Majekodunmi, O., Adeniran, J., \& Salawudeen, T. (2018). Modeling of an activated sludge process for effluent prediction-a comparative study using ANFIS and GLM regression. Environmental Monitoring and Assessment, 190, 495.

Akinyemi, FO, Ghazaryan, G, Dubovyk, O. (2020). Assessing UN indicators of land degradation neutrality and proportion of degraded land for Botswana using remote sensing based national level metrics. Land Degradation and development,1- 15. 
Bestelmeyer, B., Okin, G., Duniway, M., Archer, S., Sayre, N., Williamson, J., \& Herrick, J. (2015). Desertification, land use, and the transformation of global drylands. Frontiers in Ecology and the Environment, 13, 28-36.

Bai, X., Wang, S., \& Xiong, K. (2013). Assessing Spatial-Temporal Evolution Processes of Karst Rocky Desertification Land: Indications for Restoration Strategies. Land Degradation \& Development, 24, 47-56.

Behnke, R., \& Mortimore, M. (2016). The End of desertification? Disputing environmental change in the Drylands. Berlin: Springer-Verlag.

Chen, C., Park, T., Wang, X., Piao, S., Xu, B., Chaturvedi, R. K., Fuchs, R., Brovkin, V., Ciais, P., Fensholt, R., Tømmervik, H., Bala, G., Zhu, Z., Nemani, R. R., \& Myneni, R. B. (2019). China and India lead in greening of the world through land-use management. Nature Sustainability, 2, 122-129.

Chen, H., Shao, L., Zhao, M., Zhang, X., \& Zhang, D. (2017). Grassland conservation programs, vegetation rehabilitation and spatial dependency in Inner Mongolia, China. Land Use Policy, 64, 429-439.

Chen, J., John, R., Shao, C., Fan, Y., Zhang, Y., Amarjargal, A., Brown, D. G., Qi, J., Han, J., Lafortezza, R., \& Dong, G. (2015). Policy shifts influence the functional changes of the CNH systems on the Mongolian plateau. Environmental Research Letters, 10, 085003.

Chen, J., John, R., Zhang, Y., Shao, C., Brown, D., Ochirbat, B., Amartuvshin, A., Ouyang, Z., Dong, G., Wang, D., \& Qi, J. (2015). Divergences of Two Coupled Human and Natural Systems on the Mongolian Plateau. BioScience, 65, 559-570.

Chen, Z.-J., Li, J. B., Fang, K., Davi, N., He, X. Y., Cui, M. X., Zhang, X., \& Peng, J. J. (2012). Seasonal dynamics of vegetation over the past 100 years inferred from tree rings and climate in Hulunbei'er steppe, northern China. Journal of Arid Environments, 83, 86-93.

Cheng, L., Lu, Q., Wu, B., Yin, C., Bao, Y., \& Gong, L. (2018). Estimation of the Costs of Desertification in China: A Critical Review. Land Degradation \& Development, 29, 975-983.

Cherlet, M., Hutchinson, C., Reynolds, J., Hill, J., Sommer, S., von Maltitz, G. (Eds.), World Atlas of Desertification, Publication Office of the European Union, Luxembourg, 2018.

Copernicus Climate Change Service (C3S). (2017). ERA5: Fifth generation of ECMWF atmospheric reanalyses of the global climate. In: Copernicus Climate Change Service Climate Data Store (CDS).

Davidson, E. A., de Araujo, A. C., Artaxo, P., Balch, J. K., Brown, I. F., MM, C. B., Coe, M. T., DeFries, R. S., Keller, M., Longo, M., Munger, J. W., Schroeder, W., Soares-Filho, B. S., Souza, C. M., Jr., \& Wofsy, S. C. (2012). The Amazon basin in transition. Nature, 481, 321-328.Dong, C., Liu, X., \& Klein, K. (2012). Land degradation and population relocation in Northern China. Asia Pacific Viewpoint, 53(2), 163-177.

Ehrhardt-Martinez, K., Crenshaw, E., \& Jenkins, J. (2002). Deforestation and the Environmental Kuznets Curve: A Cross-National Investigation of Intervening Mechanisms. Social Science Quarterly, 83, 226-243.

Fan, M., Li, Y., \& Li, W. (2015). Solving one problem by creating a bigger one: The consequences of ecological resettlement for grassland restoration and poverty alleviation in Northwestern China. Land use policy, 42, 124-130.

FAO. (2020). Food and Agriculture Organization of the United Nations. http://www.fao.org/home/en/. (Accessed $1^{\text {st }}$ March 2020).

Feng, Q., Ma, H., Jiang, X., Wang, X., \& Cao, S. (2015). What Has Caused Desertification in China? Sci Rep, 5, 15998. 
Fernandez-Gimenez, M., \& Allen-Diaz, B. (1999). Testing a non-equilibrium model of rangeland vegetation dynamics in Mongolia. Journal of Applied Ecology, 36, 871-885.

Filei, A. A., Slesarenko, L. A., Boroditskaya, A. V., \& Mishigdorj, O. (2018). Analysis of Desertification in Mongolia. Russian Meteorology and Hydrology, 43, 599-606.

Graves, A., Rosa, L., Nouhou, A. M., Maina, F., \& Adoum, D. (2019). Avert catastrophe now in Africa's Sahel. Nature, 575(7782), 282-286.

Gang, C., Gao, X., Peng, S., Chen, M., Guo, L., \& Jin, J. (2019). Satellite Observations of the Recovery of Forests and Grasslands in Western China. Journal of Geophysical Research: Biogeosciences, 124, 1905-1922.

Gichenje, H, Godinho, S. (2018). Establishing a land degradation neutrality national baseline through trend analysis of GIMMS NDVI Time-series. Land Degradation and development, 29: 29852997.Gong, Z., Kawamura, K., Ishikawa, N., Goto, M., Tuya, W., Alateng, D., Yin, T., \& Ito, Y. (2020). Vegetation Dynamics and Phenological Shifts in Long-term NDVI Time Series in Inner Mongolia, China. Japan Agricultural Research Quarterly: JARQ, 54, 101-112.

Gu, Z., Wu, X., Zhou, F., Sanchez-Azofeifa, G. A., Feng, J., \& Qiu, N. (2015). Analysis of Time Scale Influences on Water and Soil Conservation Effects for Trees on Experimental Plots Using Vegetation Fractional Coverage. Forest Science, 61, 67-75.

Gumbricht, T. (2018). Detecting Trends in Wetland Extent from MODIS Derived Soil Moisture Estimates. Remote Sensing, 10, 611.

Guo, Q., Fu, B., Shi, P., Cudahy, T., Zhang, J., Xu, H., Fensholt, R., Roy, P., \& Thenkabail, P. (2017). Satellite Monitoring the Spatial-Temporal Dynamics of Desertification in Response to Climate Change and Human Activities across the Ordos Plateau, China. Remote Sensing, 9(6), 525.

Gutman, G., \& Ignatov, A. (1998). The derivation of the green vegetation fraction from NOAA/AVHRR data for use in numerical weather prediction models. International Journal of Remote Sensing, 19, 1533-1543.

Hammond, J. C., \& Kampf, S. K. (2020). Subannual Streamflow Responses to Rainfall and Snowmelt Inputs in Snow-Dominated Watersheds of the Western United States. Water Resources Research, 56, e2019WR026132.

Haniyeh, A., Shahedi, K., Jarihani, B., \& Sidle, R. (2019). Rainfall-Runoff Modelling Using Hydrological Connectivity Index and Artificial Neural Network Approach. Water, 11, 212.

Hauser, M., Orth, R., \& Seneviratne, S. I. (2016). Role of soil moisture versus recent climate change for the 2010 heat wave in western Russia. Geophysical Research Letters, 43, 2819-2826.

Helldén, U., \& Tøttrup, C. (2008). Regional desertification: A global synthesis. Global and Planetary Change - GLOBAL PLANET CHANGE, 64, 169-176.

Hirschi, M., Seneviratne, S. I., Alexandrov, V., Boberg, F., Boroneant, C., Christensen, O. B., Formayer, H., Orlowsky, B., \& Stepanek, P. (2011). Observational evidence for soil-moisture impact on hot extremes in southeastern Europe. Nature Geoscience, 4, 17-21.

Inner Mongolia Autonomous Region Statistics Bureau (IMARSB). (2018). Inner Mongolia Statistical Yearbook. Beijing: China Statistics Press.

IPBES (2018): The IPBES assessment report on land degradation and restoration. Montanarella, L., Scholes, R., and Brainich, A. (eds.). Secretariat of the Intergovernmental Science-Policy Platform on Biodiversity and Ecosystem Services, Bonn, Germany. 744 pages.

Huang, J., Yu, H., Guan, X., Wang, G., \& Guo, R. (2015). Accelerated dryland expansion under climate change. Nature Climate Change, 6, 166-171. 
Jobbágy, E. G., Sala, O. E., \& Paruelo, J. M. (2002). Patterns and controls of primary production in the patagonian steppe: a remote sensing approach. Ecology, 83, 307-319.

John, R., Chen, J., Kim, Y., Ou-yang, Z.-t., Xiao, J., Park, H., Shao, C., Zhang, Y., Amarjargal, A., Batkhshig, O., \& Qi, J. (2015). Differentiating anthropogenic modification and precipitation-driven change on vegetation productivity on the Mongolian Plateau. Landscape Ecology, 31, 547-566.

John, R., Chen, J., Lu, N., \& Wilske, B. (2009). Land cover/land use change in semi-arid Inner Mongolia: 1992-2004. Environmental Research Letters, 4, 045010.

Jorgenson, A. K., \& Burns, T. J. (2007). Effects of Rural and Urban Population Dynamics and National Development on Deforestation in Less-Developed Countries, 1990-2000. Sociological Inquiry, 77, 460-482.

Karnieli, A., Bayarjargal, Y., Bayasgalan, M., Mandakh, B., Dugarjav, C., Burgheimer, J., Khudulmur, S., Bazha, S., \& Gunin, P. (2013). Do vegetation indices provide a reliable indication of vegetation degradation? A case study in the Mongolian pastures. International Journal of Remote Sensing, $34,6243-6262$.

Li, A., Wu, J., \& Huang, J. (2012). Distinguishing between human-induced and climate-driven vegetation changes: a critical application of RESTREND in inner Mongolia. Landscape Ecology, 27, 969-982.

Li, S.-G., Eugster, W., Asanuma, J., Kotani, A., Davaa, G., Oyunbaatar, D., \& Sugita, M. (2008). Response of gross ecosystem productivity, light use efficiency, and water use efficiency of Mongolian steppe to seasonal variations in soil moisture. Journal of Geophysical Research: Biogeosciences, 113(G1), 777-793.

Liu, X. (2002). Effects and problems of ecological migration in northwest China. Chinese Rural Economics, 4, 47-52 (in Chinese).

Mayaud, J., Bailey, R., \& Wiggs, G. (2017). A coupled vegetation/sediment-transport model for dryland environments. Journal of Geophysical Research: Earth Surface, 122(4), 875-900.

Mellander, P. E., Löfvenius, M. O., \& Laudon, H. (2007). Climate change impact on snow and soil temperature in boreal Scots pine stands. Climatic Change, 85, 179-193.

Mann, H. B. (1945). Nonparametric tests against trend. Econometrica, 13, 245-259.Miao, L., Moore, J. C., Zeng, F., Lei, J., Ding, J., He, B., \& Cui, X. (2015). Footprint of Research in Desertification Management in China. Land Degradation \& Development, 26, 450-457.

Mirzabaev, A., J. Wu, J. Evans, F. García-Oliva, I.A.G. Hussein, M.H. Iqbal, J. Kimutai, T. Knowles, F. Meza, D. Nedjraoui,F. Tena, M. Türkeş, R.J. Vázquez, M. Weltz, 2019: Desertification. In: Climate Change and Land: an IPCC special report on climate change, desertification, land degradation, sustainable land management, food security, and greenhouse gas fluxes in terrestrial ecosystems [P.R. Shukla, J. Skea, E. Calvo Buendia, V. Masson-Delmotte, H.-O. Pörtner,D.C. Roberts, P. Zhai, R. Slade, S. Connors, R. van Diemen, M. Ferrat, E. Haughey, S. Luz, S. Neogi, M. Pathak, J. Petzold,J. Portugal Pereira, P. Vyas, E. Huntley, K. Kissick, M. Belkacemi, J. Malley, (eds.)]. In press. (2019). Desertification. In J. S. P.R. Shukla, E. Calvo Buendia, V. MassonDelmotte, H.-O. Pörtner,, P. Z. D.C. Roberts, R. Slade, S. Connors, R. van Diemen, M. Ferrat, E. Haughey, S. Luz, S. Neogi, M. Pathak, J. Petzold, \& P. V. J. Portugal Pereira, E. Huntley, K. Kissick, M. Belkacemi, J. Malley, (eds.) (Eds.), Climate Change and Land: an IPCC special report on climate change, desertification, land degradation, sustainable land management, food security, and greenhouse gas fluxes in terrestrial ecosystems. In press.

Muller, M. R., \& Middleton, J. (1994). A Markov model of land-use change dynamics in the Niagara Region, Ontario, Canada. Landscape Ecology, 9, 151-157. 
Munkhtsetseg, E., Kimura, R., Wang, J., \& Shinoda, M. (2007). Pasture yield response to precipitation and high temperature in Mongolia. Journal of Arid Environments, 70, 94-110.

Pang, G., Wang, X., \& Yang, M. (2017). Using the NDVI to identify variations in, and responses of, vegetation to climate change on the Tibetan Plateau from 1982 to 2012. Quaternary International, 444, 87-96.

Petri, A.E . (2017). China's 'Great Green Wall' Fights Expanding Desert. https://www.nationalgeographic.com/news/2017/04/china-great-green-wall-gobi-tenggerdesertification/. (Accessed $1^{\text {st }}$ May 2020).

Piao, S., Mohammat, A., Fang, J., Cai, Q., \& Feng, J. (2006). NDVI-based increase in growth of temperate grasslands and its responses to climate changes in China. Global Environmental Change, 16, 340-348.

Prăvălie, R. (2016). Drylands extent and environmental issues. A global approach. Earth-Science Reviews, 161, 259-278.

Ren, H., Shen, W., Lu, H., Wen, X.-Y., \& Jian, S.-G. (2007). Degraded ecosystems in China: Status, causes, and restoration efforts. Landscape and Ecological Engineering, 3, 1-13.

Ren, W., Tan, F., \& Zhang, Y. (2019). The real big thing:cold and dry northwestern China is warming and getting wet. Xinhua News. Xinhua News Agency, Beijing.

State Forestry Administration of China (SFAC). (2015). The Fifth Bulletins of Status Quo of Desertification and Sandification (BSQDS) in China.

Sherwood, S., \& Fu, Q. (2014). A Drier Future? Science, 343, 737-739.

Shi, Y., Shen, Y., Kang, E., Li, D., Ding, Y., Zhang, G., \& Hu, R. (2007). Recent and Future Climate Change in Northwest China. Climatic Change, 80, 379-393.

Song, Y., Lu, Y., Liu, T., Li, H., Yue, Z., Liu, H., \& Gao, T. (2020). Variation of vegetation fractional coverage and its relationship with climate in a desert steppe: optimization of farmland layout in a farming-pastoral ecotone using the ecological suitability index. Ecological Engineering, 150, 105834.

Sternberg, T. (2008). Environmental challenges in Mongolia's dryland pastoral landscape. Journal of Arid Environments, 72, 1294-1304.

Sternberg, T., \& Edwards, M. (2017). Desert Dust and Health: A Central Asian Review and Steppe Case Study. International Journal of Environmental Research and Public Health, 14, 1342.

Sternberg, T., Rueff, H., \& Middleton, N. (2015). Contraction of the Gobi Desert, 2000-2012. Remote Sensing, 7, 1346-1358.

Sternberg, T., Tsolmon, R., Middleton, N., \& Thomas, D. (2011). Tracking desertification on the Mongolian steppe through NDVI and field-survey data. Int. J. Digital Earth, 4, 50-64.

Tao, S., Fang, J., Zhao, X., Zhao, S., Shen, H., hu, H., Tang, Z., Wang, Z., \& Guo, Q. (2015). Rapid loss of lakes on the Mongolian Plateau. Proceedings of the National Academy of Sciences of the United States of America, 112, 2281-2286.

Thomas, D. (1993). Sandstorm in a teacup: understanding desertification in the 1990s. Geographical Journal, 159, 318-331.

Thomas, D. S. G., Knight, M., \& Wiggs, G. F. S. (2005). Remobilization of southern African desert dune systems by twenty-first century global warming. Nature, 435, 1218-1221.

Thomas, D. S. G., \& Middleton, N. J. (1994). Desertification: Exploiding the Myth. Chichester: John Wiley.

Touré, I, Larjavaara, M, Savadogo, P, Bayala, J, Yirdaw, E, Diakite, A. (2020). Land degradation along a climatic gradient in Mali: Farmers' perceptions of causes and impacts. Land Degradation and 
development, 1- 15.

UNCCD. (1994). United Nations Convention To Combat Desertification. Paris, France.

UNCCD. (2015). UNCCD Announces 2015 Winners of Land for Life Award. https://www.unccd.int/newsevents/unccd-announces-2015-winners-land-life-award. (Accessed $1^{\text {st }}$ March 2020).

UNCCD. (2019). COP14: 2-13 September New Delhi, India. https://www.unccd.int/conventionconference-parties-cop/cop14-2-13-september-new-delhiindia. (Accessed $1^{\text {st }}$ May 2020).

Urban, D. L., \& Wallin, D. O. (2017). Introduction to Markov Models. In S. E. Gergel \& M. G. Turner (Eds.), Learning Landscape Ecology: A Practical Guide to Concepts and Techniques (pp. 129-142). New York, NY: Springer New York.

Wang, J., Cheng, K., Liu, Q., Zhu, J., Ochir, A., Davaadorj, D., Li, G., Wei, H., Sonomdagva, C., Oyunchimeg, N., \& Bat-Erdene, A. (2019). Land cover patterns in Mongolia and their spatiotemporal changes from 1990 to 2010. Arabian Journal of Geosciences, 12 (24), 778.

Wang, G., Wang, P., Wang, T.-Y., Zhang, Y.-C., Yu, J.-J., Ma, N., Frolova, N., \& Liu, C.-M. (2019). Contrasting Changes in Vegetation Growth due to Different Climate Forcings over the Last Three Decades in the Selenga-Baikal Basin. Remote Sensing, 11, 426.

Wang, X., Chen, F., Hasi, E., \& Li, J. (2008). Desertification in China: An assessment. Earth-Science Reviews, 88, 188-206.

White, R. H., Battisti, D. S., \& Roe, G. H. (2017). Mongolian Mountains Matter Most: Impacts of the Latitude and Height of Asian Orography on Pacific Wintertime Atmospheric Circulation. Journal of Climate, 30, 4065-4082.

Woldendorp, G., Hill, M. J., Doran, R., \& Ball, M. C. (2007). Frost in a future climate: modelling interactive effects of warmer temperatures and rising atmospheric [CO2] on the incidence and severity of frost damage in a temperate evergreen (Eucalyptus pauciflora). Glob Chang Biol, 14, 294-308.

Wu, W., Sun, X., Epstein, H., Xu, X., \& Li, X. (2019). Spatial heterogeneity of climate variation and vegetation response for Arctic and high-elevation regions from 2001-2018. Environmental Research Communications, 2.

Wuepper, D. , Borrelli, P. , \& Finger, R. (2020). Countries and the global rate of soil erosion. Nature Sustainability, 3, 51-55.

Xu, D., Song, A., Li, D., Ding, X., \& Wang, Z. (2019). Assessing the relative role of climate change and human activities in desertification of North China from 1981 to 2010. Frontiers of Earth Science, $13,43-54$

Yang, H., Li, Y., Wu, M., Zhang, Z., \& Wan, S. (2011). Plant community responses to nitrogen addition and increased precipitation: the importance of water availability and species traits. Global Change Biology, 17(9), 2936-2944.

Zhang, B., Cao, J., Bai, Y., Zhou, X., Ning, Z., Yang, S., \& Hu, L. (2013). Effects of rainfall amount and frequency on vegetation growth in a Tibetan alpine meadow. Climatic Change, 118(118), 197-212.

Zhang, Z., Chang, J., Xu, C., Zhou, Y., Wu, Y., \& Chen, X., Jiang, S., \& Duan, Z. (2018). The response of lake area and vegetation cover variations to climate change over the Qinghai-Tibetan plateau during the past 30years. Science of the Total Environment, 635, 443-451.

Zhang, M., Wang, J., \& Li, S. (2019). Tempo-spatial changes and main anthropogenic influence factors of vegetation fractional coverage in a large-scale opencast coal mine area from 1992 to 2015. Journal of Cleaner Production, 232, 940-952. 
Zhang, M. D. A., Borjigin, E., \& Zhang, H. (2007). Mongolian nomadic culture and ecological culture: On the ecological reconstruction in the agro-pastoral mosaic zone in Northern China. Ecological Economics, 62, 19-26.

Zhang, Z., \& Huisingh, D. (2018). Combating desertification in China: Monitoring, control, management and revegetation. Journal of Cleaner Production, 182, 765-775.

Zhou, W., Gang, C., Zhou, F., Li, J., Dong, X., \& Zhao, C. (2015). Quantitative assessment of the individual contribution of climate and human factors to desertification in northwest China using net primary productivity as an indicator. Ecological Indicators, 48, 560-569.

Zhu, E., Deng, J., Zhou, M., Gan, M., Jiang, R., Wang, K., \& Shahtahmassebi, A. (2018). Carbon emissions induced by land-use and land-cover change from 1970 to 2010 in Zhejiang, China. Science of The Total Environment, 646, 930-939.

TABLE 1 Mann-Kendall test of trends of desertification and driving factors

\begin{tabular}{lllllllllll}
\hline & Desert & MSMT & AMT & MSP & AP & NS & UP & RP & BAC & IA \\
\hline Inner Mongolia & $-3.02 * * *$ & -0.42 & 0.98 & 0.49 & -0.28 & $4.41 * * *$ & $5.32 * * *$ & $-5.39 * * *$ & $5.18 * * *$ & $4.69 * * *$ \\
Mongolia & $-2.13 * *$ & -0.77 & 0.63 & 0.70 & 0.21 & $3.99 * * *$ & $5.32 * * *$ & $-1.96 * *$ & & \\
\hline
\end{tabular}

Notes: “***”, “**”, and “*” indicates that the results pass the significance test of $0.01,0.05$, and 0.1 , respectively.

TABLE 2 Changes in desertification on the Mongolian plateau between 2000 and 2019

\begin{tabular}{|c|c|c|c|c|c|c|c|c|}
\hline & \multicolumn{2}{|c|}{ Desertification in 2000} & \multicolumn{2}{|c|}{ Desertification in 2019} & \multicolumn{2}{|c|}{ Desertification changes } & \multirow{5}{*}{$\begin{array}{l}\text { Contribution } \\
\text { rate on the } \\
\text { whole } \\
\text { plateau }(\%)\end{array}$} & \multirow[t]{5}{*}{ Notes } \\
\hline & \multirow{4}{*}{$\begin{array}{l}\text { Total area } \\
\left(\mathrm{km}^{2}\right)\end{array}$} & \multirow{3}{*}{$\begin{array}{l}\text { Percentage } \\
\text { on the } \\
\text { Whole }\end{array}$} & \multirow{4}{*}{$\begin{array}{l}\text { Total area } \\
\left(\mathrm{km}^{2}\right)\end{array}$} & \multirow{4}{*}{$\begin{array}{l}\text { Percentage } \\
\text { on the } \\
\text { Whole } \\
\text { plateau }(\%)\end{array}$} & \multirow{4}{*}{$\begin{array}{l}\text { Change in } \\
\text { total area } \\
\left(\mathrm{km}^{2}\right)\end{array}$} & \multirow{4}{*}{$\begin{array}{l}\text { Change } \\
\text { in total } \\
\text { area }(\%)\end{array}$} & & \\
\hline & & & & & & & & \\
\hline & & & & & & & & \\
\hline & & plateau $(\%)$ & & & & & & \\
\hline \multicolumn{9}{|l|}{ Mongolia } \\
\hline Slight & 296562 & 63.12 & 355063 & 63.65 & 58501 & 19.73 & 66.49 & A \\
\hline Moderate & 352270 & 59.47 & 259335 & 60.41 & -92935 & -26.38 & 56.99 & $\mathrm{R}$ \\
\hline Severe & 532251 & 64.57 & 563726 & 66.30 & 31474 & 5.91 & 121.47 & A \\
\hline Extremely severe & 223562 & 54.23 & 157063 & 53.45 & -66499 & -29.75 & 56.15 & $\mathrm{R}$ \\
\hline Total desertification & 1404646 & 61.11 & 1335187 & 62.65 & -69459 & -4.94 & 41.44 & $\mathrm{R}$ \\
\hline
\end{tabular}




\begin{tabular}{|c|c|c|c|c|c|c|c|c|}
\hline \multicolumn{9}{|l|}{ Inner Mongolia } \\
\hline Slight & 173253 & 36.88 & 202733 & 36.35 & 29480 & 17.02 & 33.51 & A \\
\hline Moderate & 240088 & 40.53 & 169940 & 39.59 & -70148 & -29.22 & 43.01 & $\mathrm{R}$ \\
\hline Severe & 292049 & 35.43 & 286485 & 33.70 & -5564 & -1.91 & -21.47 & $\mathrm{R}$ \\
\hline Extremely severe & 188700 & 45.77 & 136767 & 46.55 & -51933 & -27.52 & 43.85 & $\mathrm{R}$ \\
\hline Total desertification & 894090 & 38.89 & 795925 & 37.35 & -98165 & -10.98 & 58.56 & $\mathrm{R}$ \\
\hline \multicolumn{9}{|l|}{ Whole plateau } \\
\hline Slight & 469815 & 100.00 & 557797 & 100.00 & 87981 & 18.73 & 100.00 & A \\
\hline Moderate & 592357 & 100.00 & 429275 & 100.00 & -163083 & -27.53 & 100.00 & $\mathrm{R}$ \\
\hline Severe & 824300 & 100.00 & 850211 & 100.00 & 25910 & 3.14 & 100.00 & A \\
\hline Extremely severe & 412262 & 100.00 & 293830 & 100.00 & -118432 & -28.73 & 100.00 & $\mathrm{R}$ \\
\hline All desertification & 2298735 & 100.00 & 2131112 & 100.00 & -167623 & -7.29 & 100.00 & $\mathrm{R}$ \\
\hline
\end{tabular}

Notes: $R$ means restoration; A indicates aggravating.

TABLE 3 Correlation analyses on the relationships between desertification and possible driving forces

\begin{tabular}{|c|c|c|c|c|c|c|c|c|}
\hline & & & \multicolumn{2}{|c|}{ Inner Mongolia } & \multicolumn{4}{|c|}{ Mongolia } \\
\hline \multicolumn{2}{|c|}{ Driving forces } & & \multicolumn{2}{|c|}{ Correlation analysis } & \multirow{2}{*}{$\begin{array}{c}\text { GLM regression } \\
\text { SS }(\%)\end{array}$} & \multicolumn{2}{|c|}{ Correlation analysis } & \multirow{2}{*}{$\begin{array}{l}\text { GLM regression } \\
\text { SS (\%) }\end{array}$} \\
\hline & & & $\mathrm{r}$ & $\mathrm{p}$ & & $\mathrm{r}$ & $\mathrm{p}$ & \\
\hline \multirow{4}{*}{ Climate factors } & \multirow{2}{*}{ Temperature } & MSMT & $.473^{*}$ & 0.048 & 4.05 & $.512 *$ & 0.03 & 22.39 \\
\hline & & AMT & 0.14 & 0.579 & 0.01 & 0.449 & 0.062 & 44.60 \\
\hline & \multirow{2}{*}{ Precipitation } & MSP & $-.595^{* *}$ & 0.009 & 46.25 & -0.341 & 0.166 & 3.62 \\
\hline & & AP & -0.43 & 0.075 & 27.67 & -0.296 & 0.233 & 3.83 \\
\hline \multirow{5}{*}{ Human factors } & \multirow[t]{2}{*}{ Grazing } & NS & $-.524 *$ & 0.026 & 3.26 & -0.206 & 0.412 & 12.28 \\
\hline & & UP & $-.549 *$ & 0.018 & 0 & -0.381 & 0.119 & 1.44 \\
\hline & \multirow[t]{2}{*}{ Urbanization } & $\mathrm{RP}$ & $.552 *$ & 0.017 & 0.08 & 0.426 & 0.078 & 11.84 \\
\hline & & BAC & $-.566^{*}$ & 0.014 & 9.44 & -- & -- & -- \\
\hline & Agriculture & IA & $-.639 * *$ & 0.004 & 9.24 & -- & -- & -- \\
\hline
\end{tabular}

Notes: annual mean temperature (AMT), growing season temperature (May to September) (MSMT), annual precipitation (AP), growing season precipitation (May to September) (MSP). numbers of sheep and goats (NS), rural population (RP), urban population (UP), built-up areas of cities $(B A C)$, and irrigated area $(I A) ; * P<0.05, * * P<0.01$. " + " means the factor is a positive correlation with desertification;

“.” indicates factor is a negative correlation with desertification; SS, the proportion of variances explained by the variable.

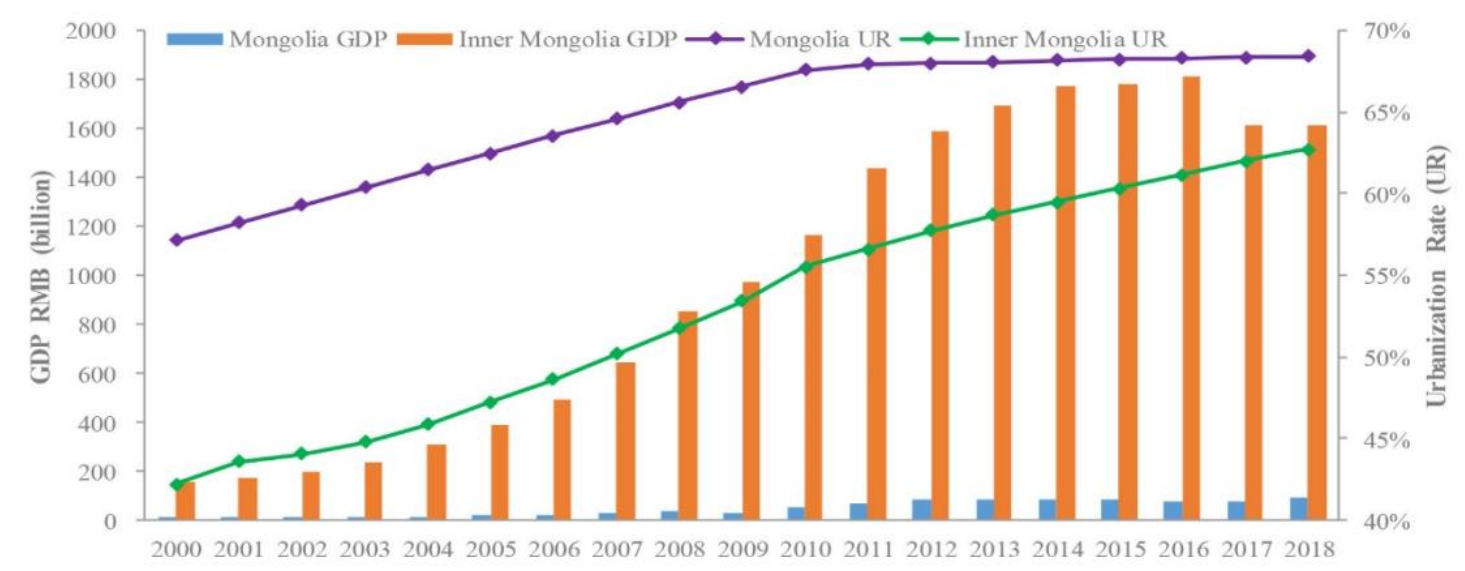

FIGURE 1 Population and GDP in Inner Mongolia and Mongolia. 

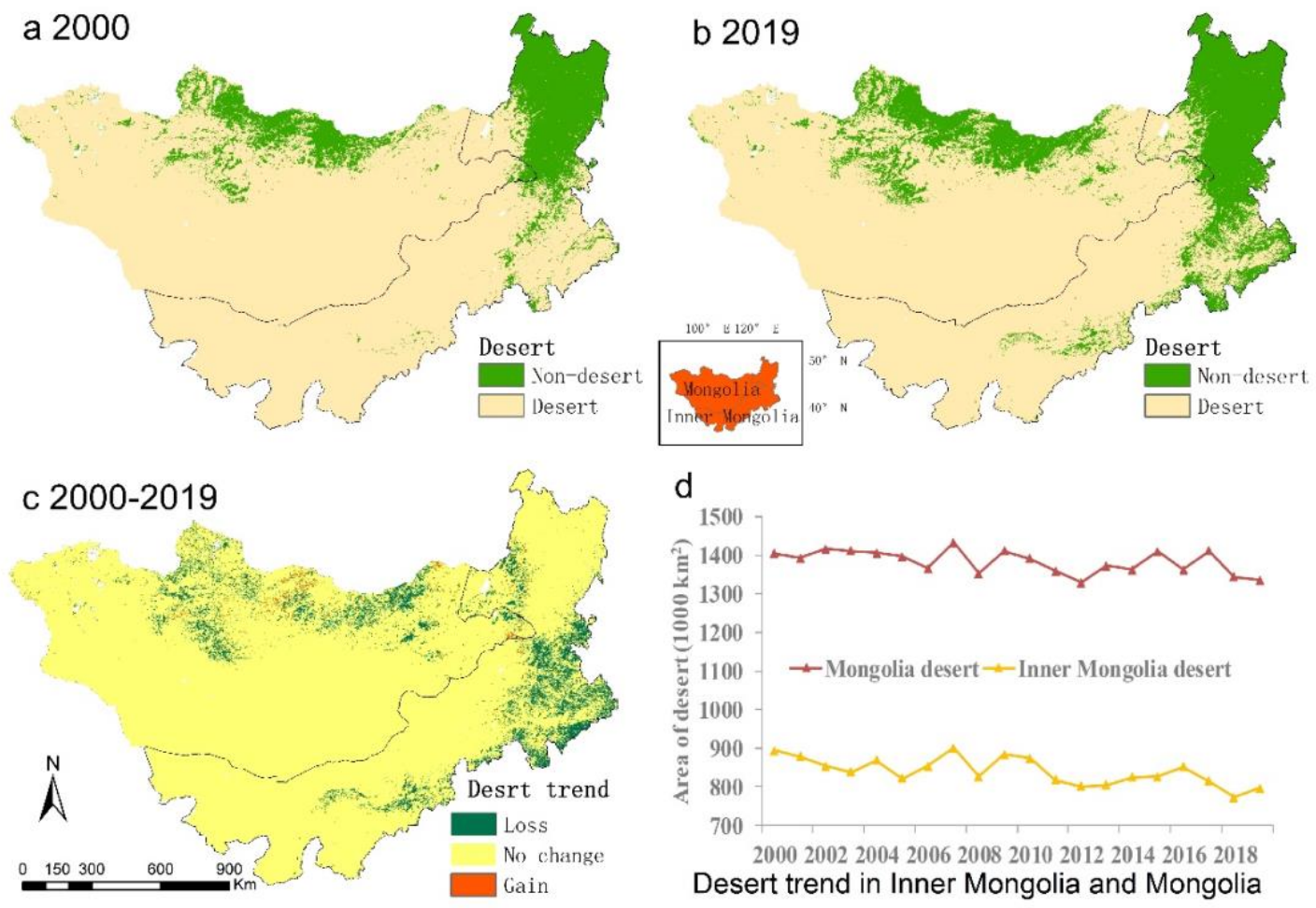

FIGURE 2 Changes in desertification on the Mongolian plateau between 2000 and 2019. (a) Distribution of desert and non-desert in 2000 and (b) in 2019. (c) Distribution of desert trends from 2000 to 2019 on the whole plateau. (d) The trend of desert and non-desert in Inner Mongolia and Mongolia from 2000 to 2019.
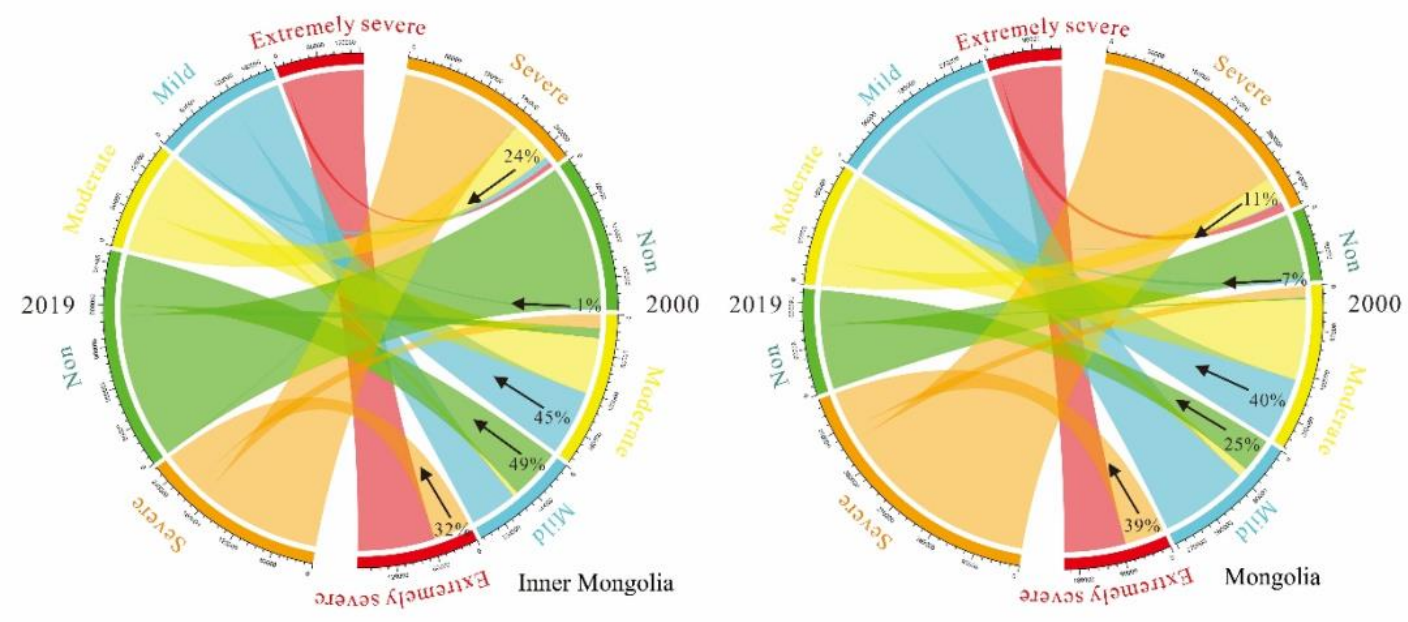

FIGURE 3 Desertification conversion on Mongolian Plateau Between 2000 and 2019. The figures show the transformation rates, expressed as \% of one class converting to another. 


\section{Changes between 2000 and 2019}

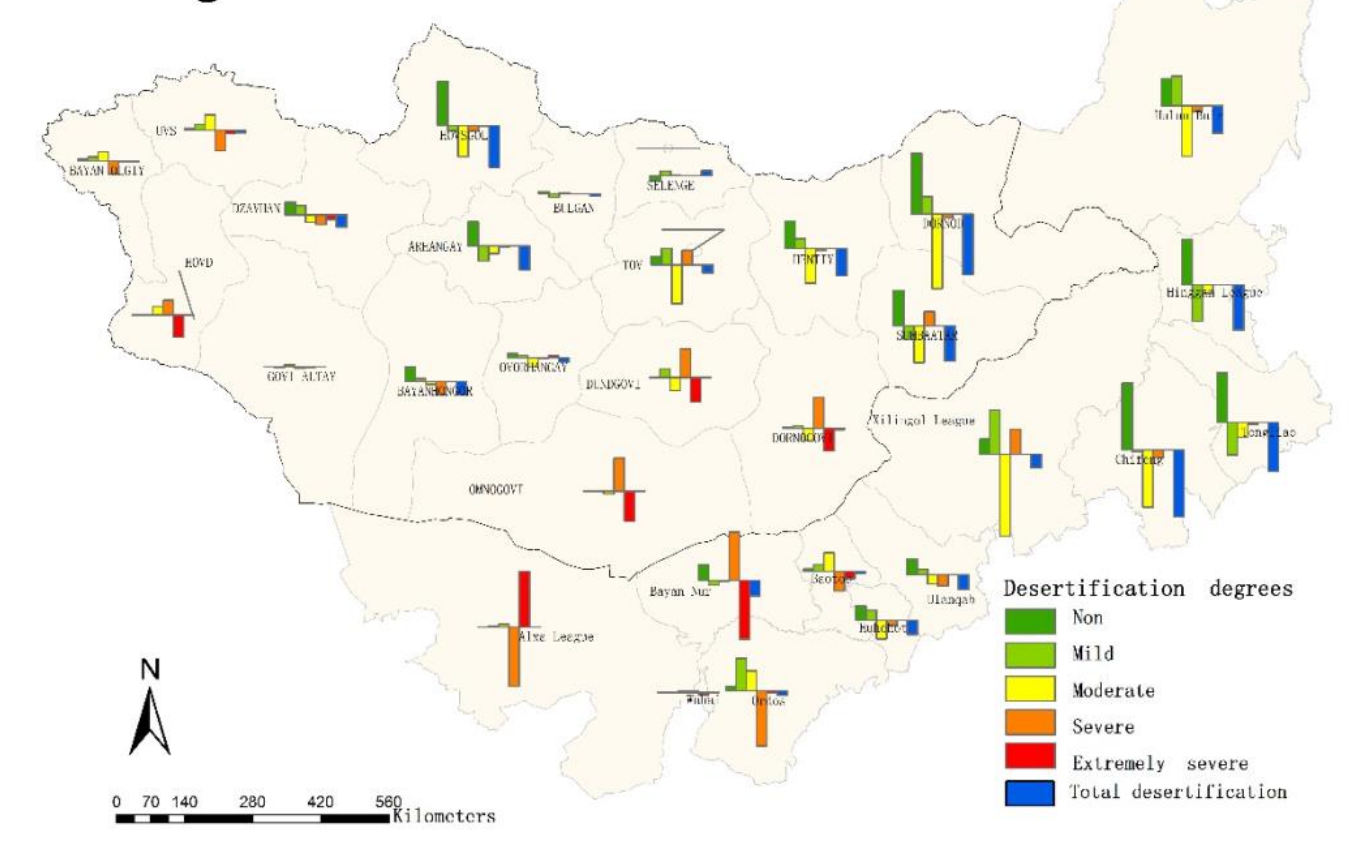

FIGURE 4 Distribution of different grades of desertification from 2000 to 2019 on the Mongolian Plateau. Those changes above the line changes are increases and those below are decreases. 


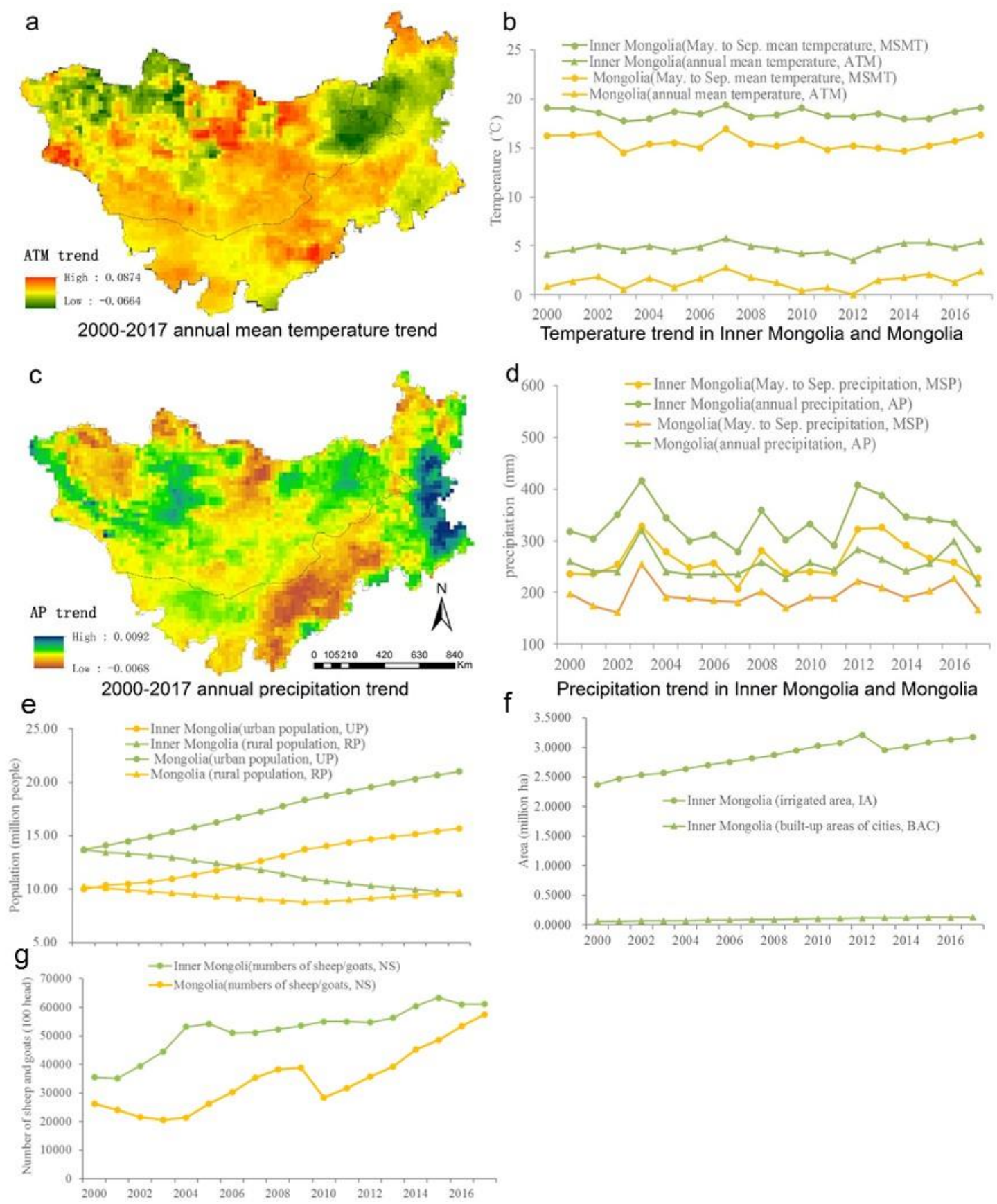

FIGURE 5 Possible driving forces in Inner Mongolia and Mongolia in the past two decades. a, the spatial distribution of 2000-2017 annual mean temperature trend in Mongolia plateau. b, annual mean temperature (AMT). and May to Sep. mean temperature (MSMT) from 2000 to 2017. c, the spatial distribution of 2000-2017 annual precipitation trend in Mongolia plateau. d, annual precipitation (AP), and May to Sep. precipitation (MSP) from 2000 to 2017. e, urban population (UP) and rural population (RP). $f$, built-up areas of cities (BAC) and irrigated area (IA) in Inner Mongolia. g, numbers of sheep and goats (NS). 


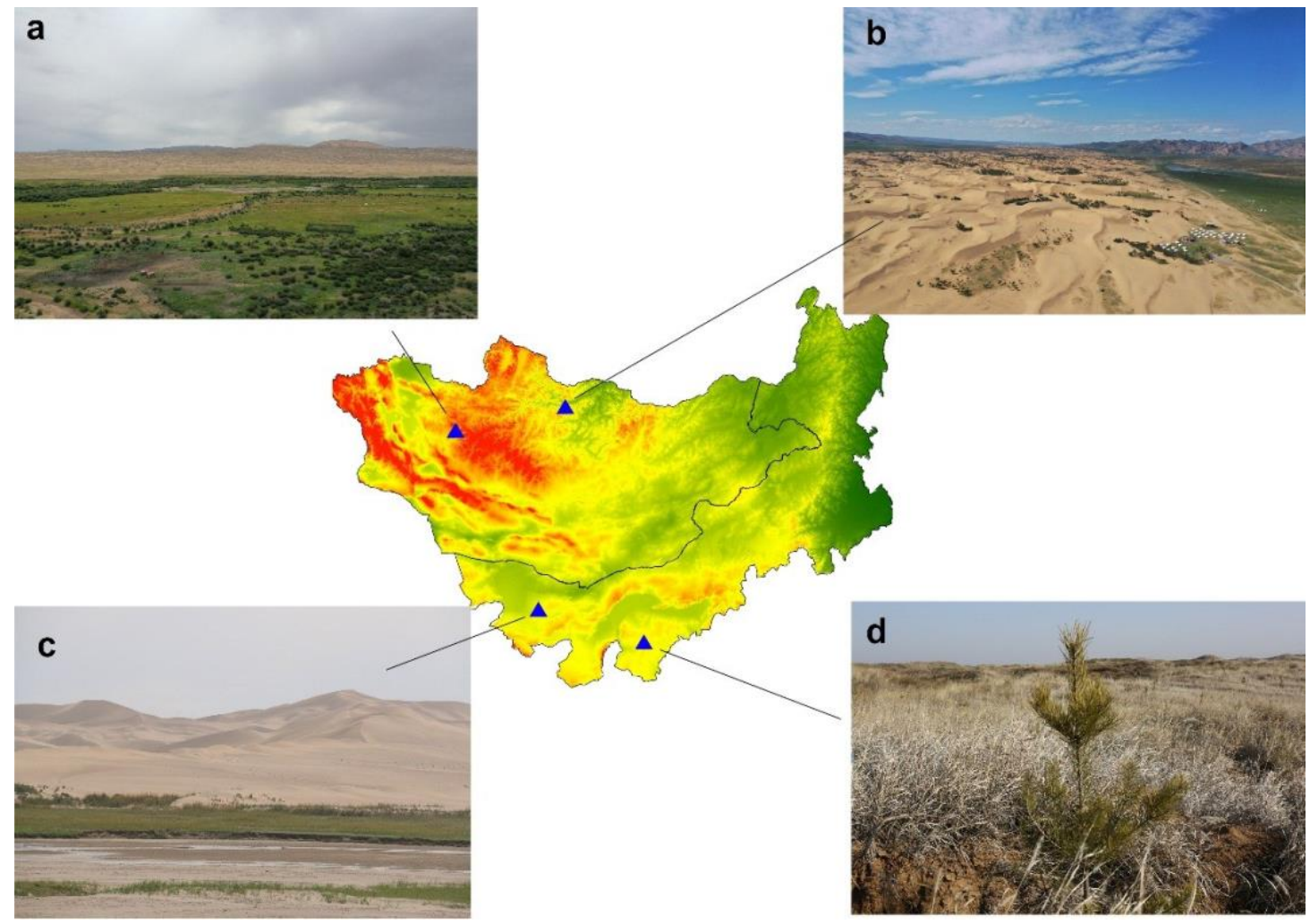

FIGURE 6 Desertification areas on the Mongolia plateau are getting green due to the increase of precipitation. a. Since the climate is getting warmer and wetter, Dzavhan is becoming more and more green (2019.8). c. The dry-up river begins to have water again with precipitation increasing, which facilitates vegetation growth nearby in Alax League, Inner Mongolia (2015.6). b. The increasing rainfall is stored in a lowland which helps the desert become green in Bulgan, Mongolia (2019.8). d. As precipitation increasing, the Kubuqi desert in the Ordos still keeps alive during the dry season (2016.11). Source: Baoli Liu. 